\title{
Real-time flood forecasting coupling different postprocessing techniques of precipitation forecast ensembles with a distributed hydrological model. The case study of may 2008 flood in western Piemonte, Italy
}

\author{
D. Cane, S. Ghigo, D. Rabuffetti, and M. Milelli \\ Regional Agency for Environmental Protection - Arpa Piemonte, Torino, Italy \\ Correspondence to: D. Cane (daniele.cane@arpa.piemonte.it) \\ Received: 10 January 2012 - Published in Nat. Hazards Earth Syst. Sci. Discuss.: - \\ Revised: 18 May 2012 - Accepted: 19 June 2012 - Published: 5 February 2013
}

\begin{abstract}
In this work, we compare the performance of an hydrological model when driven by probabilistic rain forecast derived from two different post-processing techniques. The region of interest is Piemonte, northwestern Italy, a complex orography area close to the Mediterranean Sea where the forecast are often a challenge for weather models. The May 2008 flood is here used as a case study, and the very dense weather station network allows us for a very good description of the event and initialization of the hydrological model. The ensemble probabilistic forecasts of the rainfall fields are obtained with the Bayesian model averaging, with the classical poor man ensemble approach and with a new technique, the Multimodel SuperEnsemble Dressing. In this case study, the meteo-hydrological chain initialized with the Multimodel SuperEnsemble Dressing is able to provide more valuable discharge ranges with respect to the one initialized with Bayesian model averaging multi-model.
\end{abstract}

\section{Introduction}

High resolution spatiotemporal rainfall intensity forecasts are the main input into rainfall-runoff models for flood forecast, debris-flow and landslide triggering. For supporting decision makers in order to assure a good prevention act regarding overflows or floods, environmental agencies implement deterministic models returning hydro-meteorological predictions on a regular grid with a certain spatial resolution. These numeric models approximate mathematically the underlying physical and chemical dynamics through complex non linear differential equations. However, very few operational hydrometeorological chains provide an estimate of the uncertainties of the results: rainfall forecasts, due to its complex nature, are heavily affected by many sources of uncertainty. A very exhaustive review on the different sources of uncertainties in the meteo-hydrological chain can be found in Cloke and Pappenberger (2009): they can arise from observations, from NWP model initial conditions, from NWP model parameterizations, or from the hydrological model initialization and design.

Forecast uncertainty due to the partial knowledge of the initial conditions is usually tackled by ensemble predictions systems (EPS), where a set of forecast runs are performed from perturbed initial conditions: for instance, Zappa et al. (2010) explore the propagation of uncertainty from observing systems and NWP into hydrological models, based on global model EPS and limited area model EPS.

A second class of uncertainties arises from the choices in model implementation (domain size, resolution, hydrostatic/non hydrostatic approach, physical parameterizations, etc.: an interesting experiment on how changes on a single model implementation can produce quite different rainfall extimations can be found in Stensrud et al., 2000), and can be targeted with multi-physics systems, like in Amengual et al. (2008), where different parametrizations of a single model are used to produce an ensemble of rainfall extimations to run an hydrological model, or from multi-model EPS systems, as proposed by Cloke and Pappenberger (2009). 
A further possibility is the use of already available operational NWP models to obtain a multi-model set where the final value may derive from an average, as in Raftery et al. (2005), or from a selection procedure, as in Roulston and Smith (2003), where the Best Member Dressing method is proposed. Probabilistic forecasting is a relatively new approach which may properly account for all sources of uncertainty. Recently, Sloughter et al. (2007) have extended the Bayesian model averaging (BMA) framework of Raftery et al. (2005) in order to derive probabilistic precipitation forecast via a mixture distribution. BMA belongs to the methodologies of ensemble forecasting, that considers not only a single deterministic forecast but joint forecasts coming from different models and initial conditions.

The Multimodel SuperEnsemble technique is another powerful statistical method for a better estimation of weather forecast parameters with weights calculated in a training period, originally proposed by Krishnamurti et al. (1999). Cane and Milelli (2006) have already applied it in Piemonte region (north-western Italy), a complex orographic area, to provide a more accurate forecast of several weather parameters, including precipitation (Cane and Milelli, 2010a). Furthermore, Cane and Milelli (2010b) proposed a probabilistic quantitative precipitation forecasting (QPF) evaluation with the use of a new Multimodel SuperEnsemble Dressing technique. This new approach, providing an estimation of the probability density function (PDF) of precipitation, widens our knowledge of the precipitation field characteristics, is a support for operational weather forecast and can also be used as input for the hydrological forecast chain, propagating the QPF uncertainty to the evaluation of its effects on the territory. The probabilistic scores of this technique are proven better than the Multimodel probabilistic technique originally proposed by Stefanova et al. (2002) (Cane and Milelli, 2010b).

In this paper, our purpose is to compare the performance of hydrological real-time forecasts when rainfall fields are realized as "ensemble prediction" which consider jointly predicted rainfall fields provided by several numerical models or different initial status in the same model. In particular, we focus on three different post-processing techniques of deterministic precipitation forecasts. Firstly, following Sloughter et al. (2007), Bayesian model averaging (BMA) will be taken into account using asymmetric distributions, which characterized rainfall data. Therefore, mixture models are employed where first the probability of rain is modelled and then, conditionally on the former event (it does not rain or it rains), a continuous skewed distribution is used for rainfall. Secondly Multimodel SuperEnsemble Dressing (MSD) is applied on the same data, providing adjusted probability density functions of the rainfall fields. As a benchmark, we explore the poor man ensemble (PME) technique, that consists in a merely arithmetic mean of deterministic data instead. Therefore, this methodology does not take into account uncertainty. Once forecast rainfall amounts are obtained, they are used as input for the hydrological water-balance model FEST-WB, implemented by the environmental agency Arpa Piemonte, in order to assess flood formation and propagation in hydrographical network.

We applied this simulation exercise to the case study of May 2008 flood in western Piemonte, Italy. Far from being exhaustive for a sound statistical validation of the conclusion, the results obtained shows the feasibility of a real time application of the hydrometeorological chain proposed and offer a starting point for further investigation.

The paper is organized as follows. The three different post-processing techniques and the hydrological model are explained in Sect. 2. Section 3 outlines the detail of the hydro-meteorological coupling and of the application, while in Sect. 4, we provide a description of the analysed catchments and event. In Sect. 5, we illustrate the results of the hydrological model using as input rainfall amounts forecasted by means of the three different post-processing techniques concerning the case study of May 2008 flood. Finally, Sect. 6 includes discussion on findings.

\section{Model description}

The forecasts of rainfall fields are usually performed by means of deterministic models, characterized however by two main sources of uncertainty: errors connected with starting conditions and model errors. The standard "ensemble forecasting" method requires many runs of a single model with perturbed starting values, trying to cover all the spread of the initial conditions and tackle the error coming from the first source of uncertainty. The Multimodel approach tries to solve the uncertainty coming from the incomplete representation of reality by the models. In this paper we explore three different multi-model post-processing techniques of deterministic precipitation forecasts in order to estimate the forecast rainfall probabilities: Bayesian model averaging, Multimodel SuperEnsemble Dressing and poor man ensemble: we review here some theory and set the notation for each procedure. Moreover, since we want to evaluate flood formation and propagation using as input these three different forecasts, here we give some essential information about the hydrological water-balance model FEST-WB.

\subsection{Bayesian model averaging}

Bayesian model averaging is a statistical method for combining forecasts from different models conditioning, not on a single "best" model, but on the entire ensemble of statistical models first considered. Despite the basic paradigm for this technique was introduced by Leamer (1978), the approach was basically ignored until the late 1990s and 2000s when there was an enormous amount of literature on the use of BMA (e.g. Clyde, 1999, Hoeting et al., 1999, Raftery et al., 2005, and Sloughter et al., 2007). 
Let $F_{1}, \ldots, F_{K}$ be a set of $K$ deterministic forecasts under consideration: the idea is that among these ensemble members, there is a model that comes near observations more than the others and BMA measures the uncertainty about the "best" member. As $y$ is the quantity to be forecasted on the basis of training observations $y^{T}$ and using $K$ deterministic models, the forecast PDF $p(y)$ is given by

$p(y)=\sum_{k=1}^{K} p\left(y / F_{k}\right) p\left(F_{k} / y^{T}\right)$,

where $p\left(y / F_{k}\right)$ is the forecast PDF only based on model $F_{k}$, while $p\left(F_{k} / y^{T}\right)$ is the posterior probability of model $F_{k}$ given the training data $y^{T}$; this term tells us how model $F_{k}$ fits $y^{T}$. Since the sum of all the posterior model probabilities is equal to one, they can be viewed as weights. Moreover, to quantify the uncertainty about the best member in the ensemble, the forecast $F_{k}$ is associated with a conditional PDF, that is the conditional PDF of $y$ given that $F_{k}$ is the "best" ensemble member $\left(g_{k}\left(y / F_{k}\right)\right)$. Then, the BMA predictive model is

$p\left(y / F_{k}\right)=\sum_{k=1}^{K} w_{k} g_{k}\left(y / F_{k}\right)$,

where $w_{k}$ is the posterior probability of forecast $F_{k}$, that is the best one and takes into account $F_{k}$ performance during the training period. Being $w_{k}$ 's probabilities, they add up to 1.

The normal distribution is not appropriate to fit the precipitation conditional PDF because rain height is zero in a large number of time points; where it is not zero, the distributions are very skewed. Thus a mixture model for the predictive PDF, as

$$
\begin{aligned}
& p\left(y / F_{k}\right)=\sum_{k=1}^{K} w_{k} P\left(y=0 / F_{k}\right) \\
& I[y=0]+P\left(y>0 / F_{k}\right) g_{k}\left(y / F_{k}\right) I[y>0],
\end{aligned}
$$

is implemented. $P\left(y>0 / F_{k}\right)$ is the probability of nonzero precipitation given the forecast $F_{k}$, if $F_{k}$ is the best ensemble member for that time point. The PDF of precipitation amount (given that it is not zero) is fitted through a gamma distribution.

\subsection{Poor man ensemble}

Since the 1970s the advantage of ensemble forecasting over single-run deterministic forecasting was shown by Leith (1974), proving how ensemble averaging can reduce the forecast error variance for an initial sample of normal, random initial analyses. In recent years the ensemble average has repeatedly been shown to give a more accurate forecast than a single realization of the forecast model (e.g. Du et al., 1997, Ziehmann, 2000 and Ebert, 2001). The ensemble averaging or poor man ensemble procedure provides a value for each time point, that is obtained through the arithmetic mean of ensemble members at each point. Thus,

$y=\frac{1}{K} \sum_{k=1}^{K} F_{k}$,

where $y$ is the forecasted rain height and $F_{k}, k=1, \ldots, K$, the used deterministic model forecasts, as above mentioned. This technique does not take into account any information given by observations and uncertainty given by different sources.

\subsection{Multimodel SuperEnsemble Dressing}

The Multimodel SuperEnsemble Dressing is a new technique, firstly proposed in Cane and Milelli (2010b). They evaluated probabilistic forecasts of average and maximum precipitation on Piemonte warning areas, here it is extended to station values.

In the training period the observed precipitation probability density function (PDF), conditioned to the forecasts of each model, is calculated: for a large set of model forecast values, we evaluate the observed precipitation that occurred in reality and we built a set of empirical PDFs from the frequency of occurrence of observed rainfall over a wide spectrum of possible values. The moments (mean value and variance) of the so-obtained QPFs correlate strongly $\left(r^{2}>0.98\right)$, as expected, and allow for a interpolation/extrapolation of the empirical relationship among them. This fitted relation is used to evaluate numerically the $\lambda$ and $\mathrm{k}$ parameters of a Weibull (Weibull, 1951) distribution, fitting the observed QPFs in a very suitable way.

The calculated QPFs of the given model deterministic forecasts are used to weight them with weights obtained as the inverse of the continuous rank probability score (CRPS) evaluated in the training period for each model.

A full PDF for the Multimodel dressed (super) Ensemble is thus obtained. A scheme of the procedure is depicted in Fig. 1.

A careful evaluation of the Multimodel performances versus the observations in terms of Brier skill score, roc area skill score, ignorance skill score was performed, showing a significant improvement of this technique versus the poor man ensemble probabilistic forecasts (please refer to Cane and Milelli, 2010b for a more detailed description).

\subsection{Flash - flood event spatially based distributed rainfall - runoff transformation - including water balance (FEST-WB)}

The distributed hydrological water-balance model FEST-WB computes the main processes of the hydrological cycle: evapotranspiration, infiltration, surface runoff, flow routing, subsurface flow and snow dynamics (Mancini, 1990; Montaldo et al., 2007; Rabuffetti et al., 2008). The computation domain is meshed with a net of regular square cells, within which 


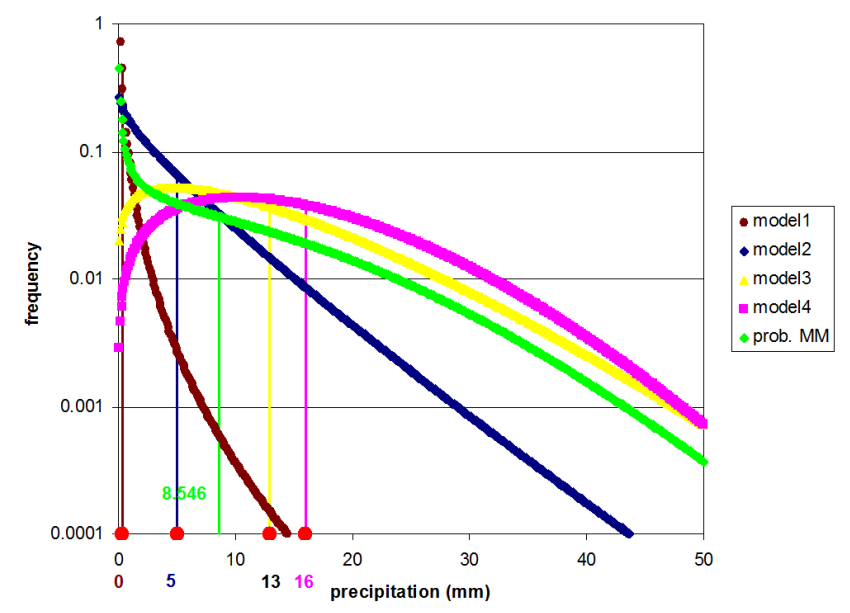

Fig. 1. Scheme of the Multimodel SuperEnsemble Dressing technique.

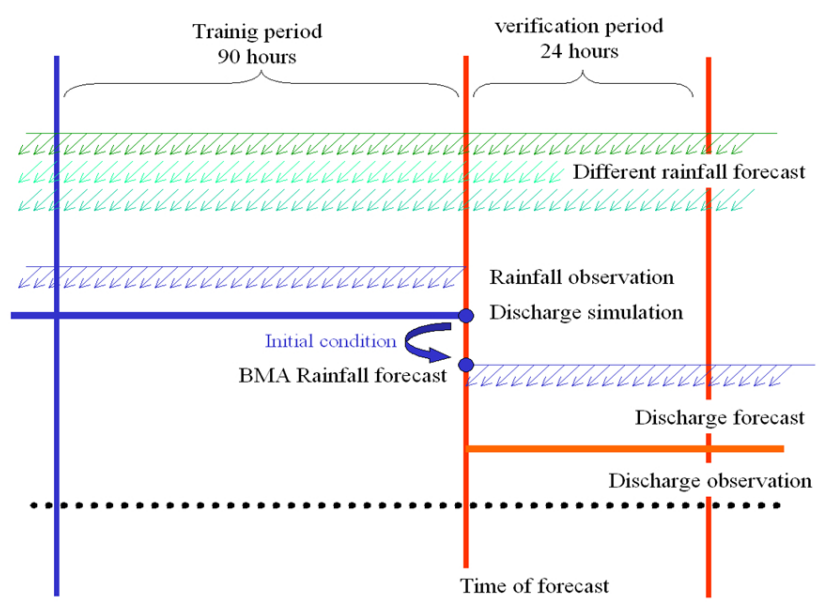

Fig. 2. Scheme of the hydro-meteorological coupling.

water fluxes are calculated. The model needs spatially distributed meteorological forcing. The observed data at ground stations are interpolated to a regular grid using the inverse distance weighting technique.

The snow model includes the snow melt and the snow accumulation dynamics. The partitioning of total precipitation, in liquid and solid phases is a function of air temperature. The snow melt simulation is based on the classical degree day model.

Soil moisture evolution for the generic cell at position $i, j$, is described by the water balance equation:

$\frac{\partial \theta_{i, j}}{\partial t}=\frac{1}{Z_{i, j}}\left(P_{i, j}-R_{i, j}-D_{i, j}-E T_{i, j}\right)$

where $P$ is the liquid precipitation rate, $R$ is runoff flux, $D$ is drainage flux, ET is evapotranspiration rate and $Z$ is the soil depth.

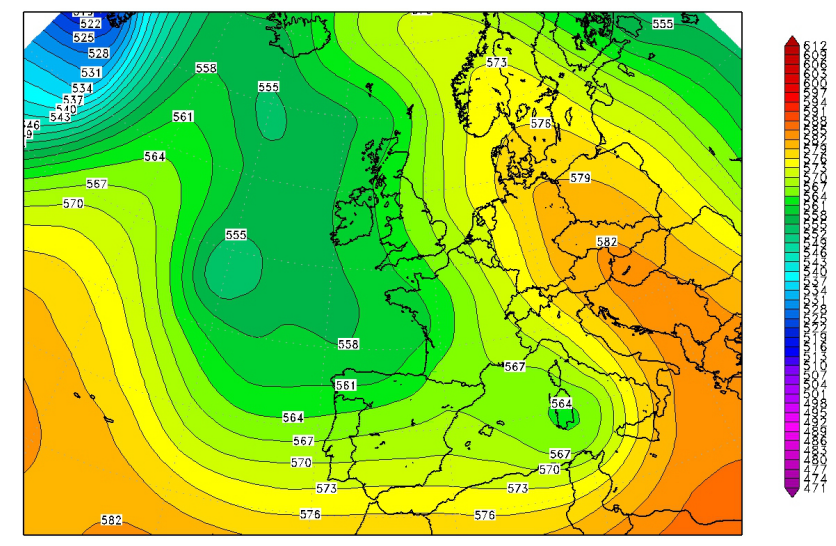

Fig. 3. Analysis of the geopotential height at $500 \mathrm{hPa}$ (dam) from ECMWF on 29 May at 12:00 UTC.

Runoff is computed according to a modified SCS-CN method extended for continuous simulation (Ravazzani et al., 2007) where the potential maximum retention, $S$, is updated at the beginning of a storm as a linear function of the degree of saturation, $\varepsilon$.

$S=S_{1} \cdot(1-\varepsilon)$

where $S_{1}$ is the maximum value of $S$ when the soil is dry (AMC 1).

The actual evapotranspiration, ET, is computed as a fraction of the potential rate tuned by the beta function that, in turn, depends on soil moisture content (Montaldo et al., 2003). Potential evapotranspiration is computed with a radiation-based equation (Priestley and Taylor, 1972).

The surface and subsurface flow routing is based on the Muskingum-Cunge method in its non-linear form with the time variable celerity (Montaldo et al., 2007).

\section{Hydro-meteorology coupling}

The information we are going to use in order to estimate rainfall heights consists of output of observed data gathered from 278 automatic weather stations of the monitoring network in Piemonte and the surrounding area run by ARPA Piemonte, and two different deterministic models: the ECMWF IFS model and three versions of the COSMO limited area model (COSMO-I7, COSMO-7, COSMO-EU: please see www.cosmo-model.org for more details about the Consortium and the model). The rain gauge network is dense enough to achieve a very good description of the study area (Fig. 4). The resolution of the IFS model grid was approximately $40 \mathrm{~km}\left(0.25^{\circ}\right)$, while the COSMO models had a resolution around $7 \mathrm{~km}\left(0.0625^{\circ}\right)$. The global model has a resolution quite coarse for the considered basins (Chisone: $560 \mathrm{~km}^{2}$, Dora Riparia: $740 \mathrm{~km}^{2}$, Pellice: $1015 \mathrm{~km}^{2}$ ), while the limited area models are representative enough, but the use 


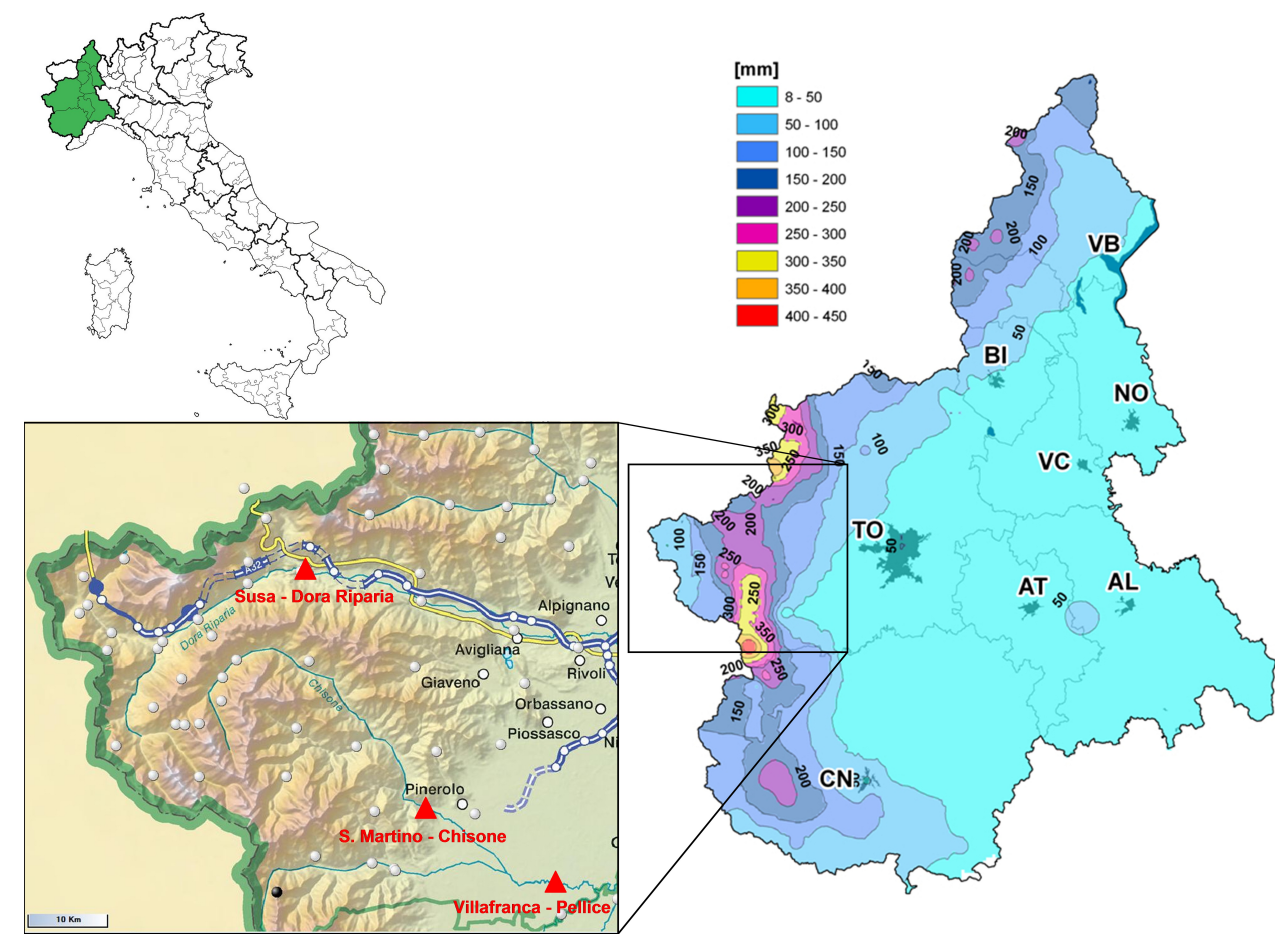

Fig. 4. On the right: total rainfall from 27 to 30 May 2008. On the left a detail of the studied area (map obtained with CAE Maps \& View ${ }^{\odot}$ ) with the Dora Riparia, Chisone and Pellice catchments, where the most important damages occurred. Triangles show the hydrometers closing the three catchments, circles represent the rain gauges.

of both a global model and limited area model gave quite successful results when combined in multi-models in Piemonte region (Cane and Milelli, 2010a).

The models are interpolated bi-linearly on station locations to allow a fair comparison with observations and to provide a model input at the same nominal resolution of the observed fields. The interpolation can of course introduce systematic errors, nevertheless the interpolated model data comparison with the observations for the whole training period of both BMA and MSD, favour the bias correction; biases can still influence the PME results. In this paper we take into account the 3-hourly cumulated precipitation concerning the flood event that from 27 to 30 May 2008 affected Piemonte region.

Concerning BMA, we choose to employ a training period of 24 data, or rather 3 days, performing model runs at different lags (1, 2, 3 and 4 steps) in order to fit the model and obtain a forecast for the following $12 \mathrm{~h}$.

Both BMA and MSD provide the predictive probability density function for each forecast time point. Since it is not possible to implement a hydrological model for each rain quantile because it is too time-consuming, we choose as input the 50th and 90th quantiles: thus we can observe if the flood trend is more or less well-included inside the range obtained using these quantiles as rainfall input.

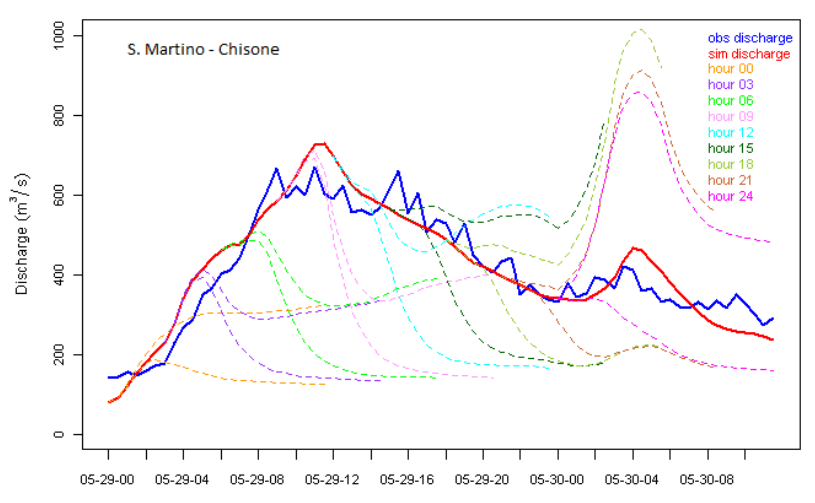

Fig. 5. Observed and FEST simulated discharge for 2930 May 2008 in San Martino Chisone station starting from BMA forecast of 50th and 90th quantiles and lags of 1,2, 3 and 4 time points.

We are not assuming here a continuous 50th/90th quantile precipitation for a very long time (of course leading to a much less probable event), because the hydrological model is re-calculated every 3-h run from the observed data and for a time range of the forecast is only $12 \mathrm{~h}$. This assumption correspond to consider a "median" and a "severe" scenario for the precipitation of the whole basin for every 3-h run of the hydrological model. 


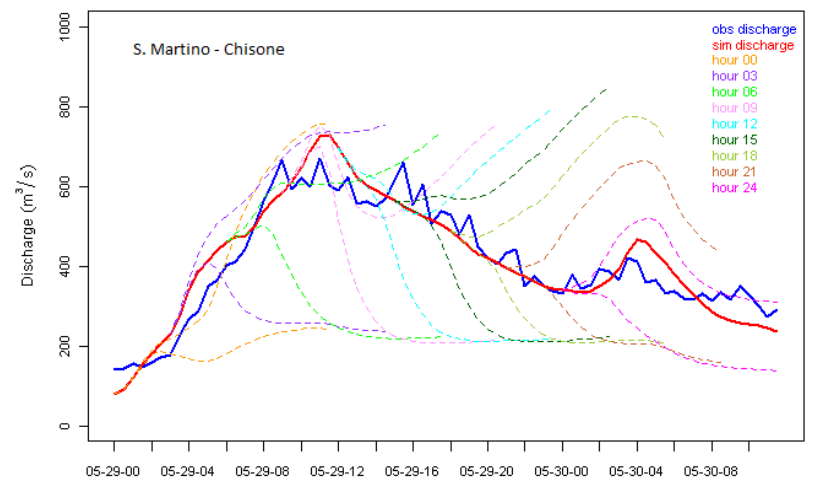

Fig. 6. Observed and FEST simulated discharge for 2930 May 2008 in San Martino Chisone station starting from MSD forecast of 50th and 90th quantiles.

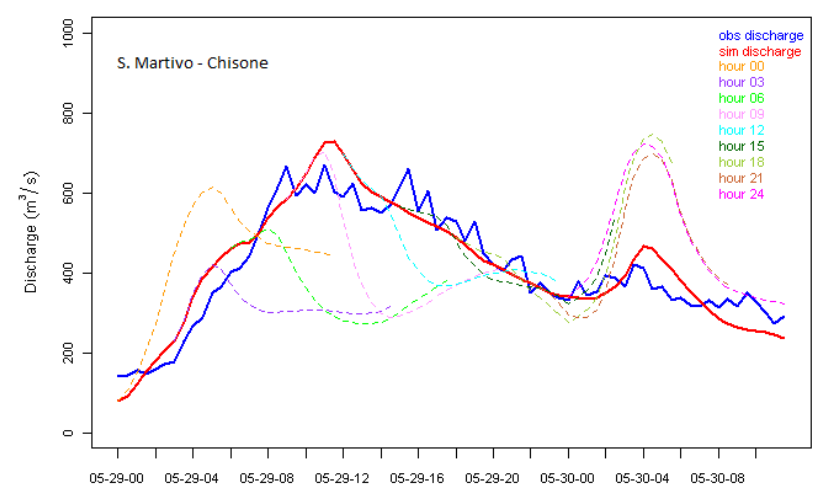

Fig. 7. Observed and FEST simulated discharge for 2930 May 2008 in San Martino Chisone station starting from PME forecast.

Moreover, using the PME technique, an arithmetic mean of the five deterministic rainfall fields is done as introduced above, the forecast is characterized by one deterministic value for each time horizon.

The coupling of the quantitative rainfall forecast with the hydrological model is addressed in a "real time" setting. The hydrological model is run every three hours updating the rainfall observations series up to the time of forecast and the rainfall forecast. The grid resolution used in this work is $1 \mathrm{~km}$, the same used for the whole Po catchment operational flood forecast. This resolution is a good compromise between hydrological model needs and rainfall field estimation from the gauge network while it is of course a challenge for deterministic quantitative rainfall forecast. The post-processing techniques here proposed are tested in the general framework to overcome this dichotomy in characteristic scales in meteorology and mountain catchment hydrology. A scheme of the hydro-meteorological coupling can be found in Fig. 2.

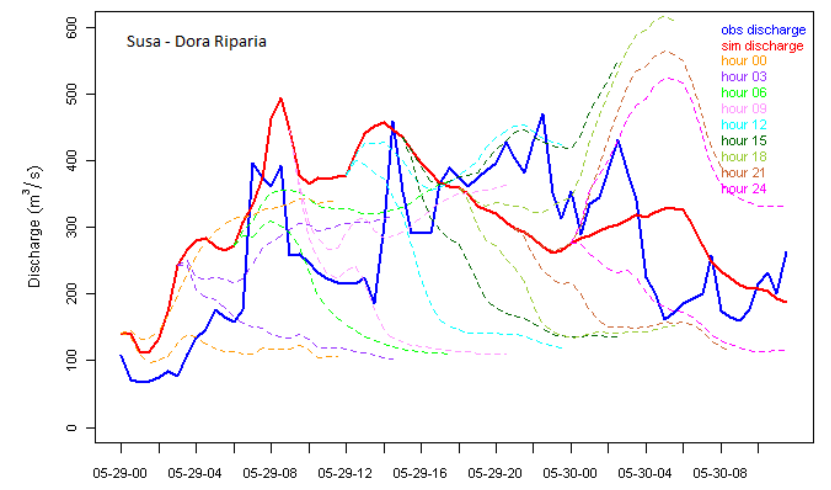

Fig. 8. Observed and FEST simulated discharge for 2930 May 2008 in Susa Dora Riparia station starting from BMA forecast of 50th and 90th quantiles and lags of 1,2,3 and 4 time points.

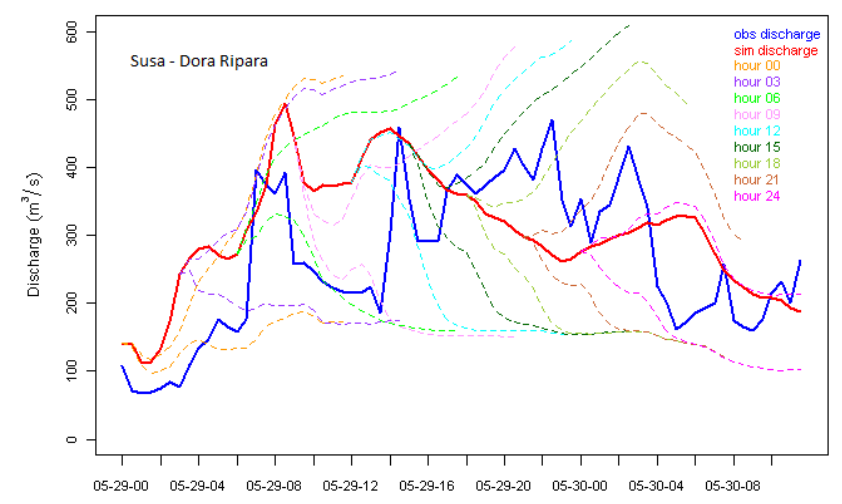

Fig. 9. Observed and FEST simulated discharge for 2930 May 2008 in Susa Dora Riparia station starting from MSD forecast of 50th and 90th quantiles.

\section{Description of the catchments and the event}

From 27 to 30 May 2008, the Piemonte region (NorthWestern Italy) was affected by heavy precipitation that triggered a number of effects on the slopes and along the rivers. An Atlantic through was stationary on the west Mediterranean and produced warm and humid southerly fluxes on Piemonte causing precipitation from 27 May in the northern part of the region. On 29 May, the minimum slowly started moving eastward onto the Ligurian sea (Fig. 3). This produced a cold air advection in the upper levels, making the humid atmosphere unstable. Precipitation intensity increased in the north with peaks in Anza and Orco valleys in the early morning. The successive rotation of the winds to the east, and their intensification, enhanced the orographic effect on the precipitation over the Western Alps, which were hit hardest from the late morning to the late afternoon, from Susa to Pellice and finally to Grana valleys.

The freezing level stayed above $3000 \mathrm{~m}$ a.s.l during the whole period so that the snow accumulation was negligible 


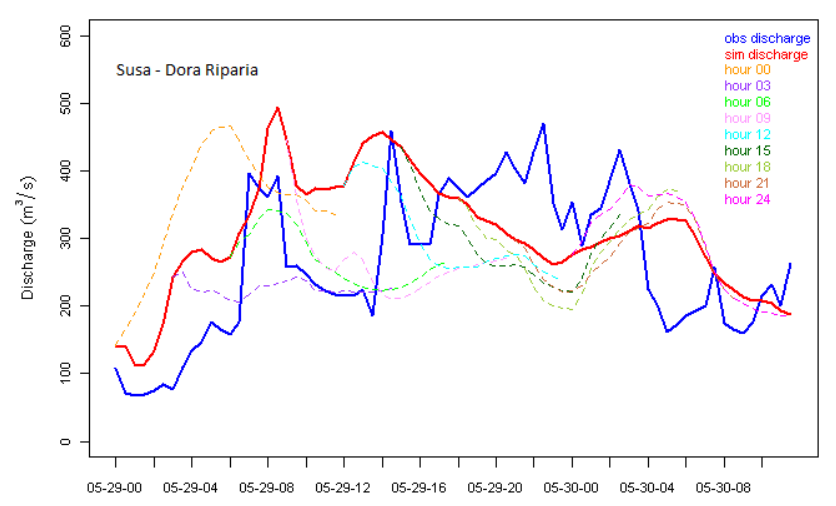

Fig. 10. Observed and FEST simulated discharge for 2930 May 2008 in Susa Dora Riparia station starting from PME forecast.

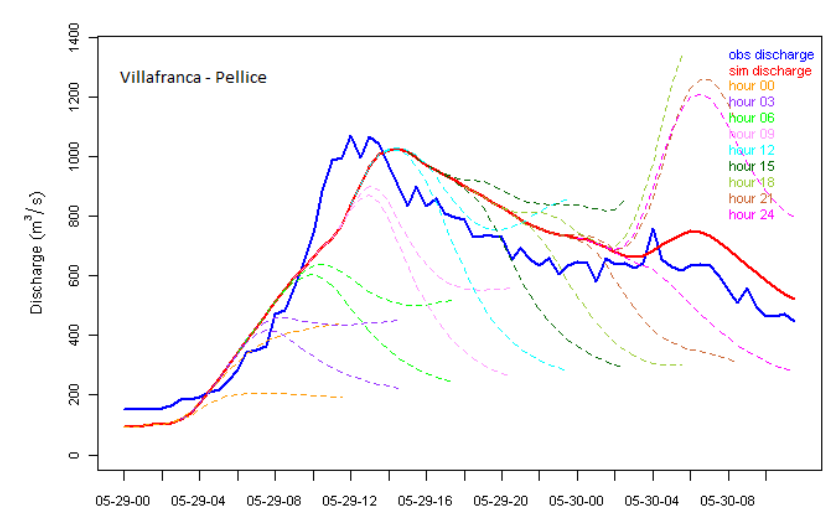

Fig. 11. Observed and FEST simulated discharge for 2930 May 2008 in Pellice Villafranca station starting from BMA forecast of 50th and 90th quantiles and lags of 1,2,3 and 4 time points.

while the melting of the antecedent snow cover below that elevation strongly contributed to amplify the total precipitation volume. Most of the alpine rain gauges records were over $200 \mathrm{~mm}$, and, in the hardest hit areas, rainfall height reached $337 \mathrm{~mm}$ and $425 \mathrm{~mm}$ during the entire event respectively in the Pellice and Germanasca valleys (Fig. 4) with maximum of $24 \mathrm{~h}$ accumulation over $200 \mathrm{~mm}$ corresponding to a return period of $20-50 \mathrm{yr}$.

Very important floods were observed along the main rivers from Dora Riparia to Grana in the western Alps and produced serious damages to streets and bridges. Flood waves propagated into the Po river which reached high danger levels upstream Torino. Shallow landslides occurred in many areas in the upstream parts of the valleys. In the northern part: Orco and Anza. In the western part: Pellice, Germasca, Po and Grana. For more details please refer to the report by Arpa Piemonte (2008).

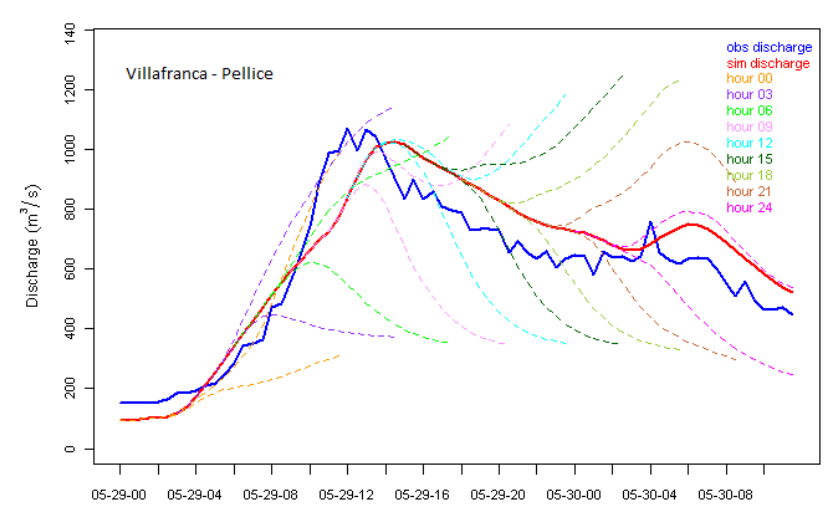

Fig. 12. Observed and FEST simulated discharge for 29-30 May 2008 in Villafranca Pellice station starting from MSD forecast of 50th and 90th quantiles.

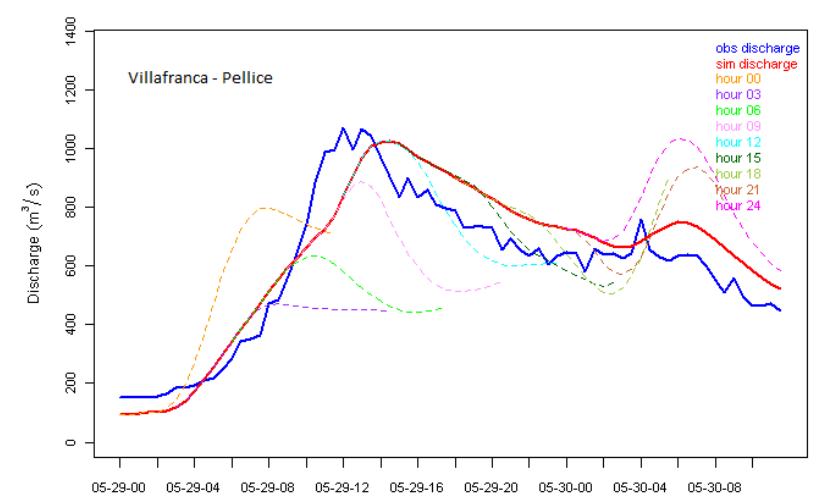

Fig. 13. Observed and FEST simulated discharge for 2930 May 2008 in Villafranca Pellice station starting from PME forecast.

\section{Results}

Figures 5-13 represent simulated discharge trends for different forecasted time points in three station mainly stricken by May 2008 event. The blue line represents the observed discharge, while the red one is simulated discharge using as input in the hydrological model the rain height observations. The other simulated discharges are obtained starting from rain heights provided by the three studied post-processing models.

Figures 5-7 show San Martino Chisone flood discharge and can be compared. All the techniques produce a quite good forecast of flood wave: indeed in 3-6h short run it is possible to forecast the flood wave evolution and instant. Looking at the second peak, hydrological model starting from BMA rain heights (Fig. 5) provides a range so large that any interpretation becomes very hard. Moreover, even if for each subsequent time point BMA decrease precipitation forecast, the figure induces to think that the second peak is bigger than the first and so it makes a much higher alarmism. 
Table 1. Error in the forecast of flood discharge between observed and FEST simulated data for each time point and each post-processing tecniques in Susa Dora Riparia station.

\begin{tabular}{|c|c|c|c|c|c|c|c|c|c|}
\hline \multirow[t]{2}{*}{ Post-processing techniques } & $\begin{array}{l}29 \text { May, } \\
\text { 00:00 UTC }\end{array}$ & $\begin{array}{l}\text { 29 May, } \\
\text { 03:00 UTC }\end{array}$ & $\begin{array}{l}29 \text { May, } \\
\text { 06:00 UTC }\end{array}$ & $\begin{array}{l}29 \text { May, } \\
\text { 09:00 UTC }\end{array}$ & $\begin{array}{l}\text { 29 May, } \\
\text { 12:00 UTC }\end{array}$ & $\begin{array}{l}\text { 29 May, } \\
\text { 15:00 UTC }\end{array}$ & $\begin{array}{l}29 \text { May, } \\
\text { 18:00 UTC }\end{array}$ & $\begin{array}{l}29 \text { May, } \\
\text { 21:00 UTC }\end{array}$ & $\begin{array}{l}30 \text { May, } \\
\text { 00:00 UTC }\end{array}$ \\
\hline & \multicolumn{9}{|c|}{ Peak discharge error $\left[\mathrm{m}^{3} \mathrm{~s}^{-1}\right]$} \\
\hline BMA: $\operatorname{sim}$ q50 & 462.97 & 255.83 & 163.91 & 42.48 & 46.92 & 84.85 & 161.91 & 253.26 & 310.40 \\
\hline BMA: sim q90 & 324.99 & 236.46 & 138.52 & 63.32 & 46.92 & 272.72 & 365.64 & 264.12 & 209.93 \\
\hline MSD: sim q50 & 404.80 & 238.94 & 147.47 & 49.86 & 46.92 & 84.85 & 161.91 & 253.25 & 310.60 \\
\hline MSD: sim q90 & 107.44 & 112.17 & 112.60 & 123.22 & 174.15 & 218.95 & 124.85 & 13.21 & 129.24 \\
\hline PME & 34.39 & 230.03 & 138.42 & 54.19 & 46.92 & 14.08 & 97.58 & 50.12 & 72.07 \\
\hline
\end{tabular}

Table 2. Error in the forecast of flood discharge between observed and FEST simulated data for each time point and each post-processing tecniques in San Martino Chisone station.

\begin{tabular}{|c|c|c|c|c|c|c|c|c|c|}
\hline \multirow[t]{2}{*}{ Post-processing techniques } & $\begin{array}{l}29 \text { May, } \\
\text { 00:00 UTC }\end{array}$ & $\begin{array}{l}\text { 29 May, } \\
\text { 03:00 UTC }\end{array}$ & $\begin{array}{l}29 \text { May, } \\
\text { 06:00 UTC }\end{array}$ & $\begin{array}{l}\text { 29 May, } \\
\text { 09:00 UTC }\end{array}$ & $\begin{array}{l}\text { 29 May, } \\
\text { 12:00 UTC }\end{array}$ & $\begin{array}{l}29 \text { May, } \\
\text { 15:00 UTC }\end{array}$ & $\begin{array}{l}29 \text { May, } \\
\text { 18:00 UTC }\end{array}$ & $\begin{array}{l}29 \text { May, } \\
\text { 21:00 UTC }\end{array}$ & $\begin{array}{l}\text { 30 May, } \\
\text { 00:00 UTC }\end{array}$ \\
\hline & \multicolumn{9}{|c|}{ Peak discharge error $\left[\mathrm{m}^{3} \mathrm{~s}^{-1}\right]$} \\
\hline BMA: $\operatorname{sim}$ q50 & 108.76 & 6.41 & 60.71 & 197.14 & 150.92 & 184.85 & 110.22 & 48.81 & 26.72 \\
\hline BMA: sim q90 & 93.53 & 71.40 & 123.23 & 197.12 & 203.68 & 332.76 & 366.16 & 314.91 & 274.04 \\
\hline MSD: sim q50 & 301.82 & 241.93 & 157.64 & 42.86 & 87.76 & 55.15 & 129.78 & 191.18 & 213.25 \\
\hline MSD: sim q90 & 51.80 & 57.86 & 52.56 & 100.05 & 108.45 & 130.11 & 67.69 & 9.27 & 141.61 \\
\hline PME & 22.68 & 239.63 & 147.12 & 42.87 & 76.93 & 55.18 & 116.90 & 135.85 & 109.94 \\
\hline
\end{tabular}

Table 3. Error in the forecast of flood discharge between observed and FEST simulated data for each time point and each post-processing tecniques in Villafranca Pellice station.

\begin{tabular}{|c|c|c|c|c|c|c|c|c|c|}
\hline \multirow[t]{2}{*}{ Post-processing techniques } & $\begin{array}{l}29 \text { May, } \\
\text { 00:00 UTC }\end{array}$ & $\begin{array}{l}\text { 29 May, } \\
\text { 03:00 UTC }\end{array}$ & $\begin{array}{l}\text { 29 May, } \\
\text { 06:00 UTC }\end{array}$ & $\begin{array}{l}29 \text { May, } \\
\text { 09:00 UTC }\end{array}$ & $\begin{array}{l}29 \text { May, } \\
\text { 12:00 UTC }\end{array}$ & $\begin{array}{l}29 \text { May, } \\
\text { 15:00 UTC }\end{array}$ & $\begin{array}{l}29 \text { May, } \\
\text { 18:00 UTC }\end{array}$ & $\begin{array}{l}29 \text { May, } \\
\text { 21:00 UTC }\end{array}$ & $\begin{array}{l}30 \text { May, } \\
\text { 00:00 UTC }\end{array}$ \\
\hline & \multicolumn{9}{|c|}{ Peak discharge error $\left[\mathrm{m}^{3} \mathrm{~s}^{-1}\right]$} \\
\hline BMA: sim q50 & 892.14 & 683.06 & 495.47 & 228.09 & 76.95 & 84.40 & 198.81 & 310.15 & 372.16 \\
\hline BMA: sim q90 & 656.82 & 639.82 & 461.93 & 199.74 & 71.44 & 84.40 & 300.25 & 159.67 & 109.83 \\
\hline MSD: sim q50 & 782.28 & 651.34 & 479.67 & 215.74 & 76.71 & 84.40 & 198.81 & 310.15 & 372.16 \\
\hline MSD: sim q90 & 64.40 & 57.77 & 19.96 & 22.91 & 119.15 & 182.15 & 128.64 & 76.28 & 306.71 \\
\hline PME & 301.18 & 627.91 & 465.10 & 211.11 & 74.07 & 84.40 & 135.59 & 163.26 & 66.81 \\
\hline
\end{tabular}

In Fig. 6 MSD succeeds to correct the precipitation forecast better than BMA, while PME (Fig. 7) provides for the second peak a quite constant value in each simulation at the same level of the first.

In Figs. 8-10 flood wave estimation at Dora Riparia Susa section is shown. Simulation done using BMA precipitation forecast (Fig. 8) identifies the 22:00 UTC peak of 29 May and another one straight after; but forecast of this one (02:00 UTC peak of 30 May) is bigger then the real discharge also in short term. Discharge in Fig. 9 seems to join these two peaks (10:00 p.m. of 29 May and 02:00 a.m. of 30 May). Forecast obtained by PME precipitations (Fig. 10) comes near to the rain observation one, under evaluating a lot 10:00 p.m. peak of 29 May.

Flood discharge trend in Pellice Villafranca section is showed in Figs. 11-13. Figure 11 presents the two peaks: looking at the forecast, it seems reach the highest peak at 6 am of 30 May, while the real flood wave is at 02:00 a.m. of 29 May. Discharge obtained starting from MSD rain heights reflects quite well the observed one, proving a good forecast in the short run ( $3 \mathrm{~h})$. Also in Fig. 13 the second peak is bigger than the observed one, but discharge levels are lower than BMA one.

Tables 1-3 provide difference between observed and simulated flood discharge for each forecast time point. Concerning BMA and MSD, peack discharge errors refer to 50th and 90th quantiles respectively.

\section{Conclusions}

On this note we intend to compare the performance of the hydrological model when the input forecasted rain height come from three different post-processing techniques. In particular, firstly Bayesian model averaging is implemented to obtain more accurate ensemble probabilistic forecasts for rainfall fields by taking into account the particular distribution (not Gaussian) of the variables under study. Indeed, meteorological variables such as rainfall data are characterized by asymmetric distributions. Thus, full modelling is performed by 
means of mixture models, where first the probability of rain is modelled and then, conditionally on the former event (it does not rain), a continuous skewed distribution is used for rainfall.

For the given test case of May 2008 flood in western Piemonte, the probabilistic discharge forecasts obtained with the Multimodel SuperEnsemble Dressing provide a good estimation of the true observed discharges in the evolution of the event, while the results obtained with BMA and poor man ensemble are unsatisfactory.

Finally, poor man ensemble provides a mean value of deterministic models for each time point, without taking into account observations.

The case study of May 2008 flood in western Piemonte makes a response providing an indicative information about the flood wave evolution only for short run ( 3 or $6 \mathrm{~h}$ before). Moreover, while FEST model starting from all the three postprocessing techniques well estimates the first flood wave, it seems to be hard well forecast the second peak. MSD, more than BMA, seems to be able to correct its estimate making a forecast at the following time points.

Even though this work examines one singular case study with the analysis of two different and independent catchments, the results obtained shows the feasibility of a real time application of the hydrometeorological chain proposed and offer a starting point for further investigation addressed to a sound statistical validation of the conclusion of this memory accounting for the reanalysis of a sufficient series of different case studies.

Acknowledgements. We thank the Deutscher Wetterdienst and MeteoSwiss for the use of their operational versions of the COSMO model in this research work. This work is partially supported by the Italian Civil Defense Department.

Edited by: L. Ferraris

Reviewed by: two anonymous referees

\section{References}

Amengual, A., Romero, R., and Alonso, S.: Hydrometeorological ensemble simulations of flood events over a small basin of Mallorca Island, Spain, Quart. J. Roy. Meteor. Soc., 134, 1221-1242, 2008.

Arpa Piemonte: Rapporto sull'evento alluvionale del 28-30 maggio 2008 http://www.arpa.piemonte.it/approfondimenti/ temi-ambientali/idrologia-e-neve/neve-e-valanghe/ relazioni-tecniche/analisi-eventi-meteorologici/eventi-2008/ 28_30_05Rapporto_finale_pt1.pdf, 2008 (in Italian).

Cane, D. and Milelli, M.: Weather forecasts with Multimodel SuperEnsemble Technique in a complex orography region, Meteorol. Z., 15, 1-8, 2006.

Cane, D. and Milelli, M.: Multimodel SuperEnsemble technique for quantitative precipitation forecasts in Piemonte region, Nat. Hazards Earth Syst. Sci., 10, 265-273, doi:10.5194/nhess-10-2652010, 2010a.
Cane, D. and Milelli, M.: Can a Multimodel SuperEnsemble technique be used for precipitation forecasts?, Adv. Geosci., 25, 1722, doi:10.5194/adgeo-25-17-2010, 2010b.

Cloke, H. L. and Pappenberger, F.: Ensemble Flood Forecasting: a review, J. Hydrol., 375, 613-626, 2009.

Clyde, M.: Bayesian model averaging and model search strategies, in: Bayesian Statistics 6, edited by: Bernardo, J. M., Dawid, A. P., Berger, J. O., and Smith, A. F. M., Oxford Univ. Press, 157$185,1999$.

Du, J., Mullen, S. L., and Sanders, F.: Short-range ensemble forecasting of quantitative precipitation, Mon. Wea. Rev., 125, 24272459, 1997.

Ebert, E. E.: Ability of a Poor Man's Ensemble to Predict the Probability and Distribution of Precipitation, Mon. Wea. Rev., 129, 2461-2480, 2001.

Hoeting, J. A., Madigan, D. M., Raftery, A. E., and Volinsky, C. T.: Bayesian model averaging: A tutorial Statistical Science Sci., 14, 382-401, 1999.

Krishnamurti, T. N., Kishtawal, C. M., Larow, T. E., Bachiochi, D. R., Zhang, Z., Williford, C. E., Gadgil, S., and Surendran, S.: Improved weather and seasonal climate forecasts from Multimodel Superensemble, Science, 285, 1548-1550, 1999.

Leamer, E. E.: Specification Searches: Ad Hoc Inference With Nonexperimental Data, Wiley, New York, 1978.

Leith, C. E.: Theoretical skill of Monte Carlo forecasts, Mon. Wea. Rev., 102, 409-418, 1974.

Mancini, M.: La modellazione distribuita della risposta idrologica: effetti della variabilità spaziale e della scala di rappresentazione del fenomeno dell' assorbimento, Tesi di dottorato, Politecnico di Milano, 1990 (in Italian).

Montaldo, N., Toninelli, V., Albertson, J. D., Mancini, M., and Troch, P. A.: The effect of background hydrometeorological conditions on the sensitivity of evapotranspiration to model parameters: analysis with measurements from an Italian alpine catchment, Hydrol. Earth Syst. Sci., 7, 848-861, doi:10.5194/hess-7848-2003, 2003.

Montaldo, N., Ravazzani, G., and Mancini, M.: On the prediction of the Toce alpine basin floods with distributed hydrologic models, Hydrol. Process, 21, 608-621, 2007.

Priestley, C. H. B. and Taylor, R. G.: On the assessment of surface heat flux and evaporation using large scale parameters, Mon. Weather Rev., 100, 81-92, 1972.

Rabuffetti, D., Ravazzani, G., Corbari, C., and Mancini, M.: Verification of operational Quantitative Discharge Forecast (QDF) for a regional warning system - the AMPHORE case studies in the upper Po River, Nat. Hazards Earth Syst. Sci., 8, 161-173, doi:10.5194/nhess-8-161-2008, 2008.

Raftery, A. E., Gneiting, T., Balabdaqui, F., and Polakowski, M.: Using Bayesian model averaging to calibrate forecast ensembles, Mon. Wea. Rev., 133, 1155-1173, 2005.

Ravazzani, G., Mancini, M., Giudici, I., and Amadio, P., in: Quantification and Reduction of Predictive Uncertainty for Sustainable Water Resources Management, edited by: Boegh, E., Kunstmann, H., Wagener, T., Hall, A., Bastidas, L., Franks, S., Gupta, H., Rosbjerg, D., and Schaake, J., IAHS Publ., 313, 407-416, 2007.

Roulston, M. S. and Smith, L. A.: Combining dynamical and statistical ensembles, Tellus, 55A, 16-30, 2003. 
Sloughter, J. M., Raftery, A. E., Gneiting, T., and Fraley, C.: Probabilistic Quantitative Precipitation Forecasting Using Bayesian Model Averaging, Mon. Wea. Rev., 135, 3209-3220, 2007.

Stefanova, L. and Krishnamurti, T. N.: Interpretation of Seasonal Climate Forecast Using Brier Skill Score, The Florida State University Superensemble, and the AMIP-I Dataset, J. Climate, 15, 537-544, 2002.

Stensrud, D. J., Bao, J.-W., and Warner, T. T.: Using Initial Condition and Model Physics Perturbations in Short-Range Ensemble Simulations of Mesoscale Convective Systems, Mon. Wea. Rev., 128, 2077-2107, 2000.
Weibull, W.: A statistical distribution function of wide applicability, J. Appl. Mech.-Trans. ASME, 18, 293-297, 1951.

Zappa, M., Beven, K. J., Bruen, M, Cofiño, A. S., Kok, K., Martin, E., Nurmi, P., Orfila, B, Roulin, E., Schröter, K., Seed, A., Szturc, J., Vehviläinen, B., Germann, U., and Rossa, A.: Propagation of uncertainty from observing systems and NWP into hydrological models: COST-731 Working Group 2., Atmos. Sci. Lett., 11, 8391, 2010.

Ziehmann, C.: Comparison of a single-model EPS with a multimodel ensemble consisting of a few operational models, Tellus, 52A, 280-299, 2000. 